\title{
FLOW ASSURANCE TECHNICAL STUDY FOR A NEW OIL DISCOVERY LOCATED IN THE EGYPTIAN WESTERN DESERT
}

\author{
M. HABIB ${ }^{1}$, M. KAOUD ${ }^{1}$, S. ALY ${ }^{2}$, M.E. AWAD ${ }^{2}$ \\ ${ }^{1}$ Khalda Petroleum Company, EGPC, Petroleum Ministr ,Egypt \\ ${ }^{2}$ Chemical Eng Department, Faculty Of Petroleum And Mining Eng, Suez University
}

\begin{abstract}
Oil and gas are discovered in remote locations far away from local market in many offshore or onshore fields around the world. It must be gathered, processed and transported through pipelines of various diameters for long distances (hundreds of miles) under varying temperature conditions. Liquid condensation occurs in natural gas pipelines in addition to liquid cut associated with gas wells. A lot of obstacles such as slugging, hydrate formation, scale formation, corrosion (erosion). Oil production also has many obstacles such as Wax deposition, Asphaltene deposition, Gel formation, Etc. These obstacles result in financial loss due to interruption of production or damage the assets. These challenges have led oil and gas companies to focus on new term called flow assurance. This paper promotes study for a new discovery in the Egyptian Western Desert and identifies some possible mitigation actions to be able to transport oil production from location to oil plant. Using OLGA multiphase transient simulator (version 2017.2.0), and Multiflash 6.1. PVT simulation to generate the fluid property tables used within OLGA.

Keywords: Flow Assurance, Oil Well, Gas Well, Slugging, Hydrate Formation, Scale Formation, Pour Point, Wax Deposition, Multiflash Simulation, OLGA
\end{abstract}

Received: Jun 08, 2020; Accepted: Jun 28, 2020; Published: Sep 12, 2020; Paper Id.: IJMPERDJUN20201177

\section{INTRODUCTION}

Flow assurance is an engineering analysis process of developing design and operating guidelines for the control of solids deposition, such as hydrates, wax, and asphaltenes in subsea systems. Depending on the characteristics of the hydrocarbons fluids to be produced, corrosion, scale deposition, and erosion may also be considered in the flow assurance process. The bulk of the flow assurance analysis should be done prior to or in the earlier Front End Engineering and Design (FEED). The requirements for each project are different and therefore project specific strategies are required for flow assurance problems. The main issues associated with the flow assurance process include: fluid characterization and flow property assessments; steady state hydraulic and thermal performance analyses; transient flow hydraulic and thermal performances analyses; system design and operating philosophy for flow assurance issues. [1].

Paraffin and Asphaltene of high molecular weight are the common responsible contributors for flow assurance issues during production and transportations of waxy crude oil through the subsea bed [2-4]. 50\% paraffin waxes could exist in waxy crude oil [5]. Small percentage of waxes would increase the pour point temperature of waxy oil, and this may result in early blockage of pipelines in the presence of temperature between the fluid and the weather temperature [6]. Wax molecules appearance is liquid phase in crude oil under fluid region at reservoir temperature and pressure, where the fluid viscosity is independent of temperature. In cold condition, 
wax molecules crystallize and solidify [7]. Essentially, the deposition of the wax results in a significant decrease in the solubility of the wax, then the wax particles completely freeze and become gel, reducing the cross-sectional area of the pipelines [6]. The gel formed in total phase change the waxy oil, which decreases efficiency of transportation. Waxy oil gel has been considered as incompressible single phase fluid at the pressure required for restarting pipelines filled with gelled crude oil [8]. The complex nature of waxy oil gel as a result of high wax concentration had implemented in simple assumptions. As a result, product pressure was assumed constant along and across pipelines [9]. The simplified assumptions has led to an over designed and excessive size of pumps and pipeline systems, demanding expensive facilities from oil industries [10].

In July 2018, announced a new oil discovery on the exploration prospect located in the Egyptian Western Desert. That discovery confirmed the high exploration and production potential of the area, reason why a fast track execution plan was established based on the drilling of new wells and using the already existing infrastructures of Oil Plant and export oil pipeline to treat and then ship to the last terminal. Two production wells B-1X and B-2X connected to a manifold via a $10 \mathrm{~km}$ total 4 " ND flow line $(6.6 \mathrm{~km}$ for B1 and $3.4 \mathrm{~km}$ for B2) from the manifold the overall production shall be transported to the oil plant via pipeline 130km 10" ND trunk line as shown in Figure 1. The production fluid presents significant attention points. In fact, it has a high pour point (above $30^{\circ} \mathrm{C}$ ) and also a high wax content leading to potential severe inline wax deposition risks.

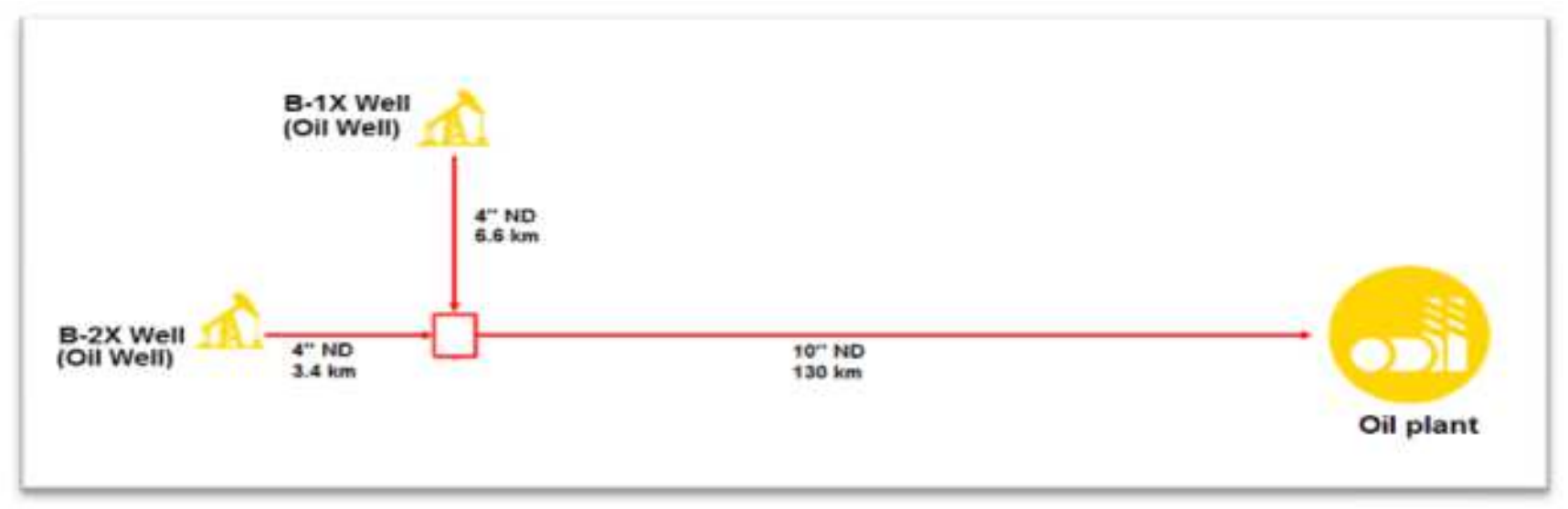

Figure 1: Oil wells flow lines to oil plant diagram

\section{METHODOLOGY}

\subsection{Data collection:}

Table 1: Data of reservoir fluid of Well: B-1X \& Well: B-2X

\begin{tabular}{|c|c|c|c|c|c|c|c|}
\hline \multirow{2}{*}{ 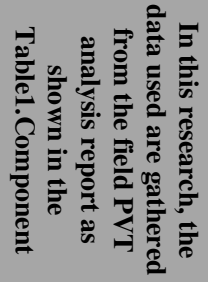 } & \multicolumn{2}{|c|}{$\begin{array}{c}\text { Well: B-1X Reservoir } \\
\text { Fluid } \\
\end{array}$} & \multicolumn{2}{|c|}{ Well: B-2X Reservoir Fluid } & \multicolumn{3}{|c|}{ Data Summary of Wells } \\
\hline & Mol\% & Weight \% & Mol\% & Weight \% & & B-1X & B-2X \\
\hline $\mathrm{N} 2$ & 0.062 & 0.009 & 0.139 & 0.029 & Reservoir Pressure (psig) & 6342 & 7233 \\
\hline $\mathrm{CO} 2$ & 0.529 & 0.126 & 1.498 & 0.495 & Reservoir Temperature $\left({ }^{\circ} \mathrm{F}\right)$ & 253 & 274 \\
\hline $\mathrm{H} 2 \mathrm{~S}$ & 0.000 & 0.000 & 0.000 & 0.000 & Saturation pressure at $274^{\circ} \mathrm{F}(\mathrm{psig})$ & 122.4 & 1077 \\
\hline $\mathrm{CH} 4$ & 1.983 & 0.173 & 15.216 & 1.832 & API of stock tank oil & 35.1 & 38.5 \\
\hline $\mathrm{C} 2$ & 0.370 & 0.060 & 7.224 & 1.630 & Properties of Oil at Reservoir Pressur & & \\
\hline
\end{tabular}




\begin{tabular}{|c|c|l|l|l|l|c|c|}
\hline C3 & 1.049 & 0.251 & 4.845 & 1.604 & Density, (gms/cc) & 0.8215 & 0.7648 \\
\hline $\mathrm{iC} 4$ & 0.797 & 0.251 & 1.232 & 0.537 & $\begin{array}{l}\text { Formation Volumetric Factor } \\
\text { (RB/STB) }\end{array}$ & 1.0519 & 1.2322 \\
\hline $\mathrm{nC} 4$ & 2.145 & 0.677 & 2.966 & 1.294 & $\begin{array}{l}\text { Properties of Oil at Saturation } \\
\text { Pressure:- }\end{array}$ & & \\
\hline $\mathrm{iC5}$ & 2.188 & 0.857 & 1.830 & 0.991 & Density, (gms/cc) & 0.7723 & 0.6947 \\
\hline $\mathrm{nC5}$ & 3.401 & 1.332 & 2.528 & 1.369 & Formation Volumetric Factor (RB/STB) & 1.1190 & 1.3565 \\
\hline $\mathrm{C} 6$ & 7.797 & 3.554 & 4.473 & 2.820 & Differential Liberation:- & & \\
\hline MCP & 0.059 & 0.027 & 0.029 & 0.019 & Residual oil density at 60 F, (gm/ml) & & 0.8390 \\
\hline Benzene & 0.984 & 0.417 & 0.770 & 0.452 & Gas Oil ratio, (scf/STB residual oil) & & 353.9 \\
\hline C7+ & 78.636 & 92.264 & 57.248 & 86.926 & & & \\
\hline
\end{tabular}

\subsection{Process simulation}

2.2.1. The simulation software OLGA: The flow assurance analysis has been performed using OLGA multiphase transient simulator (version 2017.2.0), while the fluid property tables used within OLGA have been generated with Multiflash 6.1.

\subsubsection{Simulation model}

The fluids have been characterized using Soave-Redlich-Kwong EOS modifications to the Van der Waals equation of state (vdW EOS), focused on the temperature by promoting two-variable dependency for "a": $\boldsymbol{a}=\boldsymbol{a}(\boldsymbol{T}, \boldsymbol{w})$

" $\boldsymbol{a}$ " expressed not only as a function of temperature $(\boldsymbol{T})$, but also as a function of the shape (sphericity) of the molecules $(\boldsymbol{w}$, Pitzer's acentric factor as a measure of the sphericity and configuration of molecule). The Soave-Redlich-Kwong EOS expression:

$$
P=\frac{R T}{v-b}-\frac{\alpha a}{v(v+b)},\left(P+\frac{\alpha a}{v(v+b)}\right)(v-b)=R T
$$

Where,

- $\quad \mathrm{P}$ is the gas pressure $\bullet \mathrm{R}$ is the gas constant,

- $\mathrm{T}$ is temperature, $\bullet \mathrm{v}$ is the molar volume $(\mathrm{V} / \mathrm{n})$,

- $\quad \mathrm{a}$ is a constant that corrects for attractive potential of molecules

- $\quad \mathrm{b}$ is a constant that corrects for volume, and $\bullet \operatorname{Tr}$ is reduced temperature

$$
\alpha=\left[1+\left(0.48508+1.55171 w-0.15613 w^{2}\right)(1-\sqrt{T r}]^{2}\right.
$$

The effect of a centric factor and temperature on the attractive term is introduced through "a". Expression becomes unity at $\operatorname{Tr}=1$

$$
a=0.427480 \frac{R^{2} T_{c}^{2}}{P_{c}}, b=0.086640 \frac{R T_{c}}{P_{c}}
$$

Where:

- $\quad \boldsymbol{T}_{\boldsymbol{c}}$ is the temperature at the critical point, and

- $\quad \boldsymbol{P}_{\boldsymbol{c}}$ is the pressure at the critical point.

Soave-Redlich-Kwong EOS defined, 


$$
A=\frac{\alpha a P}{R^{2} T^{2}}, B=\frac{b P}{R T} Z^{3}-Z^{2}+\left(A-B-B^{2}\right) Z-A B=0
$$

Where $\mathrm{Z}$ is the compressibility factor

For mixtures, Soave proposed a "little" modification to the mixing rules with which dealt with introducing the use of "binary interaction parameters" (kij)

$(\alpha a)_{m}=\sum \sum y_{i} y_{j}(\alpha a)_{i j} ;(\alpha a)_{i j}=\sqrt{(\alpha a)_{i}(\alpha a)_{i}}\left(1-K_{i j}\right), \mathrm{b}_{\mathrm{m}}=\sum_{\mathrm{i}} \mathrm{y}_{\mathrm{i}} \mathrm{b}_{\mathrm{i}}$

\subsubsection{Simulation study steps}

The flow assurance analysis has been performed using OLGA multiphase transient simulator (version 2017.2.0), while the fluid property tables used within OLGA have been generated with Multiflash 6.1.

\subsubsection{Assumptions}

The following list of assumptions has been used in the present study:

- It is considered that the pipeline is laid above ground. No embedment or other pipe-soil interactions that might allow the pipeline to become partially buried.

- No solar radiation has been accounted in heat exchange calculation.

- The maximum considered gas velocity limit is $20 \mathrm{~m} / \mathrm{s}$, while for liquids it is $5 \mathrm{~m} / \mathrm{s}$.

- The Erosion Velocity Ratio (mixture velocity/erosion velocity) limit is $<1$.

\subsubsection{Scenarios}

Seven scenarios are promoted for the pipeline at worst ambient temperature of $\left(10^{\circ} \mathrm{C}-25^{\circ} \mathrm{C}\right)$ and the pressure at the $130 \mathrm{~km}$

- 10in Trunk line Inlet \& Outlet in each case is shown in Figure2 for each scenario.

- (Case 1) presents the 130km 10" trunk line at the full production flow rate of 10200bbl/d with associated water flowrate of $1500 \mathrm{bbl} / \mathrm{d}$, using cluster B1x oil viscosity (Conservative assumption) and at receiving pressure of 2 barg at Oil pand without pressure control valve (PCV) at the trunk line outlet. It was found that the wells production can be delivered without violating the trunk line design pressure of 100barg. With a maximum backpressure of 63.5 barg at the production manifold. On the other hand, the flow will be associated with severe slugs at the trunk line outlet.

- (Case 2) has the same basis as Case 1, except using fluid viscosity mixture of 2 (B2) :1 (B1). It was found that the wells production can be delivered without violating the trunk line design pressure of 100barg. With a maximum backpressure of 51 barg at the production manifold. On the other hand, the flow will be associated with severe slugs at the trunk line outlet.

- (Case 3) has the same basis as Case 1, except using a 2" size pressure control valve (PCV) at the 10" trunk line outlet to mitigate the slug flow. It was found that the wells production can be delivered without violating the trunk line design pressure of 100barg. With a maximum backpressure of 81 barg at the production manifold, with less severe slugs at the trunk line outlet. 
- (Case 4) has the same basis as Case 3, In addition to simulating the 4" flowlines from B2 \& B1 clusters to the manifold to calculate the pressure drop through the flow lines as well. The wells production of oil, water and associated gas have been simulated as per table (2-1) and using the associated HC fluid for each flowline and a mixture HC fluid of 2 (B2) :1 (B1) through the trunk line. It was found that the wells production can be delivered without violating the trunk line design pressure of 100barg. With a maximum backpressure of 69 barg at B2 \& B1 wells and 55 barg at the production manifold.

- (Case 5) has the same basis as Case 4, but simulating B2 cluster production only. The wells productions of oil, water and associated gas have been simulated. It was found that B2 wells production can be delivered without violating the trunk line design pressure of 100barg. With a maximum backpressure of 56 barg at the B2 well head and 42 barg at the production manifold.

- (Case 6) has the same basis as Case 4, but with higher associated water flow rate of 8000 BWPD to evaluate the effect of the water injection on the slug flow mitigation. It was found that water injection is not mitigating the slug flow.

- (Case 7) has the same basis as Case 4, using the most updated production flow rate of 9000bbl/d with associated water flow rate of $2150 \mathrm{bbl} / \mathrm{d}$, associated gas flowrate of $2.3 \mathrm{MMscfd}$ and at receiving pressure of 2 barg at the Oil plant with a pressure control valve (PCV) at the trunk line outlet. It was found that the wells production can be delivered without violating the trunk line design pressure of 100barg. With a maximum backpressure of 70 barg at the B2 cluster, 66 barg at B1 cluster and 56 barg at the production manifold, on the other hand, the flow will be associated with slugs at the trunk line outlet.As mentioned above, slug flow behavior is expected at the trunk line outlet as well as at the receiving separator. Different methods have been tested, but the most effective one is represented by the pressure increase upstream the receiving facilities. (flow chocking) The existence of the 2.3 MMscfd of the associated gas is limiting the liquid wall friction in the sections where the liquid would have fully occupied the pipeline inner surface and consequently reducing the backpressure at the wellheads. Based on Lab Test, the high wax content requires a regular pigging program for cleaning purposes due to the expected in-line wax deposition.

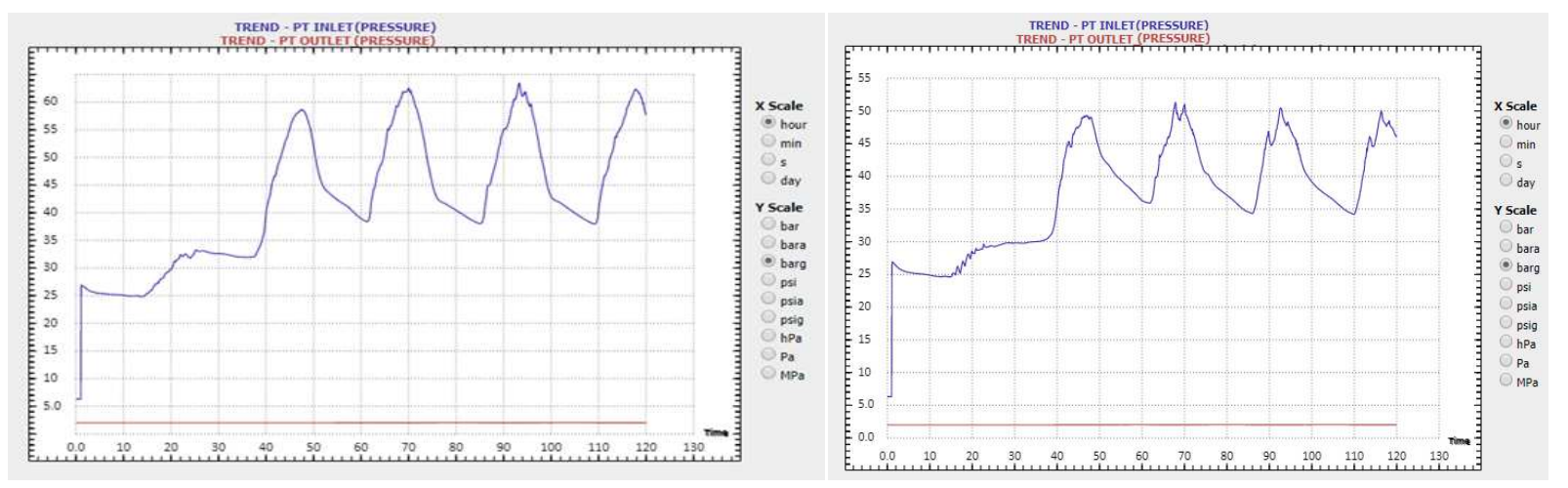



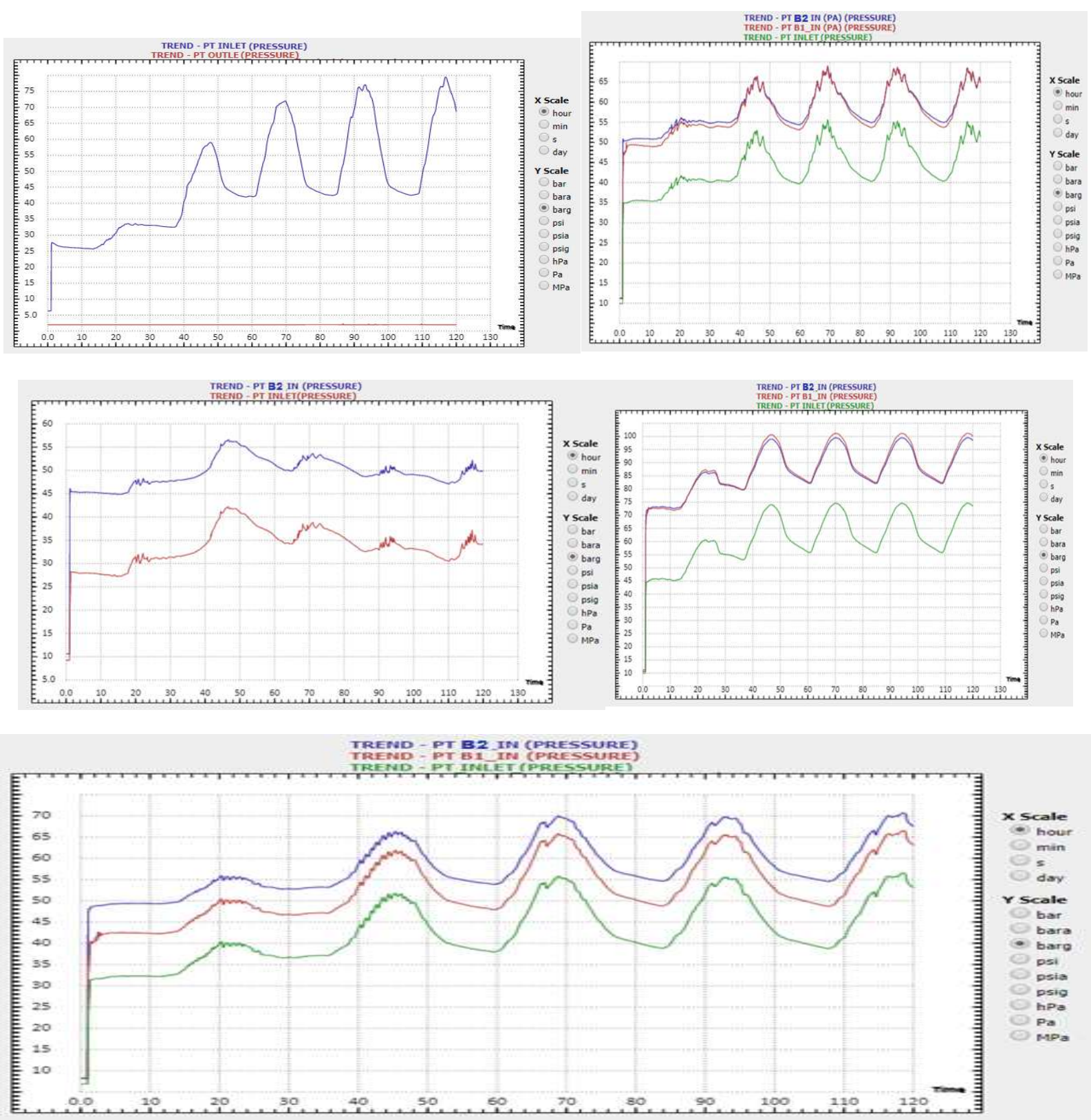

Figure 2: Pressure at the 130km - 10in Trunk line Inlet \& Outlet in each case

\section{RESULTS AND DISCUSSIONS}

\section{Simulation Results}

Different simulation cases including different production fluids blends as shown in Table 2.

Table 2: Results of the hydraulic analysis

\begin{tabular}{|l|l|l|l|l|l|l|l|l|}
\hline Case & & Case 1 & Case 2 & Case 3 & Case 4 & Case 5 & Case 6 & Case 7 \\
\hline Ambient T & {$\left[{ }^{\circ} \mathbf{C}\right]$} & $10-25$ & $10-25$ & $10-25$ & $10-25$ & $10-25$ & $10-25$ & $10-25$ \\
\hline HC fluid & - & B2 & B2 & B2 & B2,B1 & B2 & B2,B1 & B2,B1 \\
\hline
\end{tabular}




\begin{tabular}{|c|c|c|c|c|c|c|c|c|}
\hline & & & & & $\&$ Mix & & $\&$ Mix & $\&$ Mix \\
\hline Viscosity & - & B1 & $\begin{array}{ll}2: 1 & \text { B2 } \\
\text { B1 } & \end{array}$ & B1 & $\begin{array}{ll}2: 1 & \text { B2 } \\
\text { B1 } & \\
\end{array}$ & B2 & $\begin{array}{ll}2: 1 & \text { B2 } \\
\text { B1 } & \end{array}$ & $\begin{array}{ll}2: 1 & \text { B2 } \\
\text { B1 } & \end{array}$ \\
\hline Gas Rate & [MMscfd] & 2.5 & 2.5 & 2.5 & 2.5 & 2.5 & 2.5 & 2.3 \\
\hline Oil Rate & [STBD] & 10,200 & 10,200 & 10,200 & 10,200 & 5,700 & 10,200 & 9,000 \\
\hline Water Rate & [STBD] & 1,500 & 1,500 & 1,500 & 1,500 & 500 & 8,000 & 2,150 \\
\hline Total Liquid & [STBD] & 11,700 & 11,700 & 11,700 & 11,700 & 6,200 & 18,200 & 11,150 \\
\hline WC & {$[\%]$} & 12.8 & 12.8 & 12.8 & 12.8 & 8.1 & 44.0 & 19.3 \\
\hline $\begin{array}{ll}\text { Fixed restriction } \\
*\end{array}$ & & - & - & $2 "$ & $2^{\prime \prime}$ & $2 "$ & $2^{\prime \prime}$ & $2^{\prime \prime}$ \\
\hline $\begin{array}{ll}\Delta P & \text { (fixed } \\
\text { restriction) }\end{array}$ & [bar] & - & - & 10 & 10 & 10 & 12 & 8 \\
\hline 4" FL & & - & - & - & yes & yes & yes & Yes \\
\hline P Manifold & [barg] & 63.5 & 51.3 & 81 & 55 & 42 & 75 & 56 \\
\hline$P$ well (A2) & [barg] & - & - & - & 69 & 56 & 99 & 70 \\
\hline P Well (B1) & [barg] & - & - & - & 69 & - & 101 & 66 \\
\hline Drain Rate & bbl/d & 20000 & 20000 & 20000 & 20000 & 20000 & 20000 & 20000 \\
\hline V Surge & $\mathbf{m}^{3}$ & 79 & 36 & 1.3 & 7.5 & 7.7 & 75 & 27.3 \\
\hline Drain Rate & bbl/d & 35000 & 35000 & 35000 & 35000 & 35000 & 35000 & 35000 \\
\hline V Surge & $\mathbf{m}^{3}$ & 1.5 & 8.4 & 0 & 0 & 0 & 22 & 10.8 \\
\hline Flow Stability & - & $\begin{array}{l}\text { Slug } \\
\text { flow }\end{array}$ & $\begin{array}{l}\text { Slug } \\
\text { flow }\end{array}$ & $\begin{array}{l}\text { Slug } \\
\text { flow }\end{array}$ & $\begin{array}{l}\text { Slug } \\
\text { flow }\end{array}$ & $\begin{array}{l}\text { Slug } \\
\text { flow }\end{array}$ & $\begin{array}{l}\text { Slug } \\
\text { flow }\end{array}$ & $\begin{array}{l}\text { Slug } \\
\text { flow }\end{array}$ \\
\hline
\end{tabular}

(*) The sensitivity cases $(3,4,5,6 \& 7)$ have been developed using a fixed resistance (2" ID) upstream the receiving facilities at the oil plant to evaluate its impact on the slug mitigation.

Winter Case, Above Ground Scenario (Ambient temperature 1 Celsius)

- Wax Appearance Temperature 51.9 Celsius.

- Max formed Wax Temperature 31.2 Celsius. Max Fluid Temperature 32.5 Celsius.

There will be formed Wax with max thickness of $7.45 \mathrm{~mm}$ at pipeline inlet as per below 
Figure 3. After $84.1 \mathrm{Km}$ and at elevation difference of $24 \mathrm{~m}$, temperature would drop to around

-0.0073 Celsius. Which will form solid particles blocking flow inside pipe (e.g. ice pellets).

At the last $9 \mathrm{Km}$ of the pipeline, the elevation difference would be around $16 \mathrm{~m}$, and

temperature would drop to around -0.11 Celsius. This will form solid particles blocking

flow inside pipe (e.g. ice pellets).

\section{Summer Case, Above Ground Scenario (Ambient temperature 49 Celsius)}

- Wax Appearance Temperature 51.9 Celsius.

- $\quad$ Max formed Wax Temperature 49 Celsius. Max Fluid Temperature 49.007 Celsius

Max formed wax thickness is $0.0023 \mathrm{~mm}$ at pipeline outlet as per below Figure3.

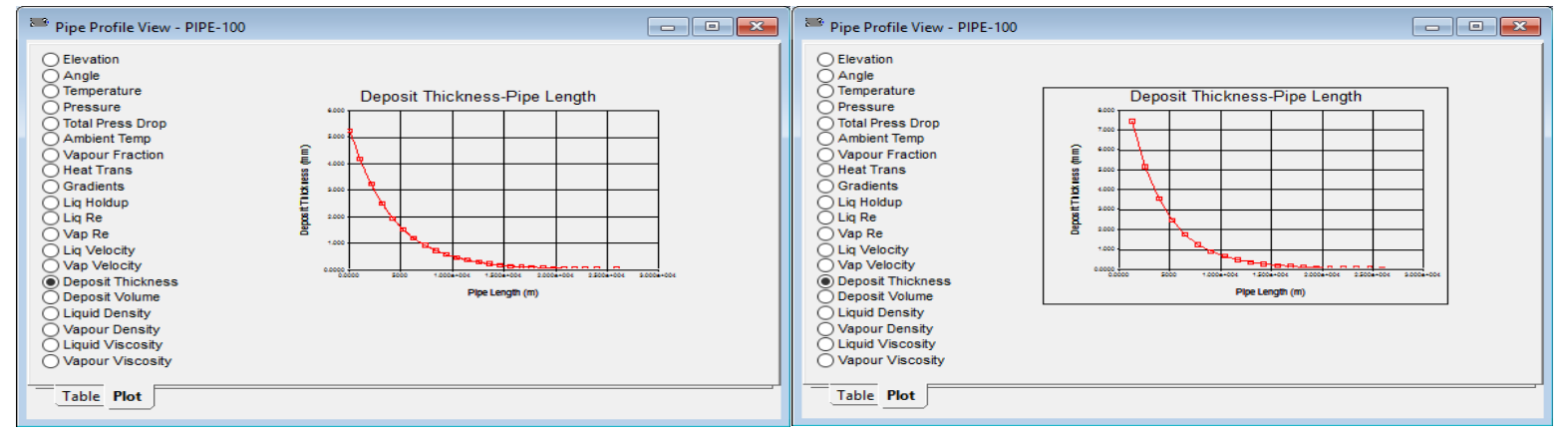

Figure 3: Deposit (Wax) Thickness for first $30 \mathrm{~km}$ in summer and winter times.

\section{CONCLUSIONS}

- Input data were considered according to data collected

- Cases of simulation were considered to include worst conditions.

- Summer case: Max well head flow rate, lowest press. and lowest fluid temp. of wells.

- Winter case: Max well head flow rate, Lower Pressure and fluid temperature of each well.

- Software OLGA multiphase transient simulator (version 2017.2.0) was used for simulation.

- $\quad$ Fluid property tables used in OLGA have been generated with Multiflash 6.1.

- $\quad$ Simulation was performed to include all scenarios.

\section{REFERENCES}

1. Kaczmarski, A. A. and Lorimer, S. E. (2001), "Emergence of Flow Assurance as a Technical Discipline Specific to Deepwater: Technical Challenges and Integration into Subsea Systems Engineering", OTC 13123, Offshore Technology Conference, Houston.

A. Aiyejina, D.P. Chakrabarti, A. Pilgrim, M.K.S. Sastry, Wax formation in oil pipelines: a critical review, Int. J. Multiphase Flow 37 (2011) 671-694.

2. E. Rogel, C. Ovalles, J. Vien, M. Moir, Asphaltene characterization of paraffinic crude oils, Fuel 178 (2016) 71-76. 
3. Y. Lei, S. Han, J. Zhang, Effect of the dispersion degree of asphaltene on wax deposition in crude oil under static conditions, Fuel Process. Technol. 146 (2016) 20-28.

4. J.A. Ajienka, C.U. Ikoku, The effect of temperature on the rheology of waxy crude oils, Soc. Petrol. Eng. (1991) SPE-23605$M S$.

5. C. Bai, J. Zhang, Effect of carbon number distribution of wax on the yield stress of waxy oil gels, Ind. Eng. Chem. Res. 52 (2013) 2732-2739.

6. K. Oh, M. Jemmett, M. Deo, Yield behavior of gelled waxy oil: effect of stress application in creep ranges, Ind. Eng. Chem. Res. 48 (2009) 8950-8953.

7. I.F. Luthi, Waxy crude oil characterization and experimental study of the restart of a line blocked with gelled waxy crude, Proceedings - SPE Annual Technical Conference and Exhibition, 2013, pp. 5433-5443.

8. G.T. Chala, S.A. Sulaiman, A. Japper-Jaafar, W.A.K.W. Abdullah, Study on influence of flow rates on voids in waxy crude oil subjected to dynamic and static cooling, J. Petrol. Sci. Eng. 9 (2015) 1587-1594.

9. H.S. Lee, P. Singh, W.H. Thomason, H.S. Fogler, Waxy oil gel breaking mechanisms: adhesive versus cohesive failure, Energy Fuels 22 (2008) 480-487. 

